\title{
EFEITO DA DEXAMETASONA NA FERTILIDADE DO TOURO
}

\author{
(Effect of dexamethasone on bull fertility)
}

\begin{abstract}
Romildo Romualdo Weiss, Tatita Elly Treml, Ana Claudia Machinski Rangel de Abreu, Melina Andrea Formighieri Bertol, Luiz Ernandes Kozicki, Tácia Gomes Berstein, Marília de Oliveira Koch ${ }^{1}$
\end{abstract}

\begin{abstract}
${ }^{1}$ Correspondência; rrweiss@bol.com.br
RESUMO: A fertilidade de reprodutores bovinos é a condição essencial para o progresso genético e alta produtividade animal, podendo ser afetada por diversas patologias testiculares e pelo uso de alguns medicamentos de ação sistêmica. $\mathrm{O}$ objetivo deste trabalho foi avaliar o efeito da administração de dexametasona sobre o comportamento sexual, parâmetros espermáticos e dosagem de testosterona sérica de touros. Foram utilizados 6 touros com idade em torno dos 5 anos e escore de condição corporal semelhante, os quais foram divididos em dois grupos, controle $(n=3)$ e tratado $(n=3)$. O experimento foi dividido em dois períodos, preliminar e experimental, com duração de 18 semanas. Após a padronização das características avaliadas durante o período preliminar, os animais do grupo tratado receberam doses diárias de $20 \mathrm{mg}$ de dexametasona intramuscular durante 5 dias. Foram analisados e comparados os dados obtidos nos dois períodos para ambos os grupos. As características avaliadas foram: comportamento sexual, volume, $\mathrm{pH}$ e concentrações de frutose e ácido cítrico do ejaculado, motilidade progressiva, turbilhonamento, vigor, concentração, morfologia espermática e dosagem de testosterona plasmática. Dos parâmetros avaliados, houve diferença significativa $(P<0,5)$ somente na dosagem de testosterona sérica.
\end{abstract}

Palavras-chave: bovinos; glicocorticoides; sêmen

ABSTRACT:. Fertility of breeder cattle is the essential condition for genetic progress and animal high productivity, being affected by several testicular diseases and by the use of a few drugs of systemic action. The objective of this study was to evaluate the effect of dexamethasone administration on the sexual behavior, sperm parameters and serum testosterone dosage of bulls. There were used six bulls with age around five years and similar body condition score, which were divided into two groups: control $(n=3)$ and treated $(n=3)$. The experiment was separated in two periods: preliminary and experimental, lasting 18 weeks. After the patterning of features evaluated during the preliminary period, the animals of the treated group received daily intramuscular dexamethasone doses of $20 \mathrm{mg}$ for 5 days. There were analyzed and compared the data obtained in the two periods for both groups. The features evaluated were: sexual behavior, volume, $\mathrm{pH}$ and concentrations of fructose and citric acid from the ejaculated, progressive motility, turbulence, vigor, concentration, sperm morphology and plasmatic testosterone dosage. From the parameters evaluated, there was significant difference $(P<0.5)$ only in serum testosterone dosage.

Key Words: cattle; glucocorticoids; semen 
Efeito da dexametasona na fertilidade do touro.

\section{INTRODUÇÃO}

A fertilidade é a condição essencial para - progresso genético e alta produtividade animal, podendo ser alterada por condições que afetem a libido ou a cópula (impotência coeundi) e/ou habilidade dos espermatozoides fecundarem 0 oócito (impotência generandi) (VAN CAMP, 1997).

Diversas patologias testiculares afetam a fertilidade em maior ou menor grau e podem ser de origem genética, congênita ou adquirida. Dentre as alterações adquiridas destaca-se a degeneração testicular (NASCIMENTO \& SANTOS, 2003), considerada uma das causas mais importantes de subfertilidade e infertilidade em touros que servem a campo no Brasil (VALE FILHO et al. 1981) e que pode ser induzida pelo uso prolongado de alguns medicamentos de ação sistêmica, como a ivermectina e a dexametasona (HORN et al, 1999; PIMPAO et al. 2005).

Visto que 0 grupo dos glicocorticoides é de grande importância no tratamento de diversas afecções, tendo seu uso bastante amplo, tornouse necessária a execução deste trabalho cujo objetivo foi avaliar o efeito da administração de dexametasona sobre 0 comportamento sexual, parâmetros espermáticos e dosagem de testosterona sérica de touros.

\section{MATERIAL E MÉTODOS}

\section{Animais}

Foram utilizados seis touros provenientes de uma Central de Reprodução, sendo quatro touros da raça Jersey, um da raça Nelore e um da raça Red Angus, os quais apresentavam idade em torno de cinco anos e escore de condição corporal semelhante, classificada como $4( \pm 0,5)$, numa escala de 1-5. Durante o experimento, os animais foram alimentados com dieta balanceada, pastoreio em piquetes individuais com água e sal mineral $a d$ libitum.

\section{Delineamento experimental}

O experimento foi conduzido num período de 18 semanas, tempo correspondente a duas espermatogêneses, e dividido em períodos preliminar e experimental. Durante a fase preliminar, coletou-se um ejaculado de cada touro com vagina artificial na presença de fêmea no cio uma vez por semana, por um período de nove semanas, com o objetivo de avaliar o perfil seminal durante uma espermatogênese e a libido dos touros, com um escore variando de 0 a 6 . As amostras de sêmen foram avaliadas imediatamente após a colheita, observando-se macroscopicamente 0 volume do ejaculado por meio de tubos coletores graduados.

Microscopicamente avaliou-se turbilhonamento com uma gota de sêmen depositada em lâmina aquecida a $37^{\circ} \mathrm{C}$, a motilidade espermática e 0 vigor utilizando uma gota de sêmen entre lâmina e lamínula também aquecidas a $37^{\circ} \mathrm{C}$ para determinação do percentual de células móveis, em microscópio óptico com objetiva de 40x.

A concentração espermática foi determinada com espermiodensímetro com base na turbidez do ejaculado e a leitura efetuada em tabela própria. A avaliação da morfologia dos espermatozoides para determinar 0 percentual de defeitos morfológicos foi realizada em microscopia de contraste de fase após esfregaço celular do sêmen, previamente conservado em solução de formol salina. Para a aferição do $\mathrm{pH}$ do sêmen utilizou-se fitas indicadoras de $\mathrm{pH}$. Os exames bioquímicos do sêmen (frutose e ácido cítrico) foram realizados semanalmente durante cinco semanas. Foram realizadas dosagens de testosterona 
sanguínea por meio do método de ELISA também semanalmente durante quatro semanas e, posteriormente essas dosagens foram realizadas por quatro dias consecutivos até o primeiro dia da aplicação da dexametasona.

Iniciou-se a fase experimental com a divisão dos animais em dois grupos, grupo controle $(n=3)$ e grupo tratado $(n=3)$. O grupo tratado recebeu aplicações diárias de $20 \mathrm{mg}$ de dexametasona intramuscular por cinco dias consecutivos e, o grupo controle recebeu aplicações equivalentes de solução salina $0,9 \%$. Procedeu-se a colheita de ejaculado de cada touro uma vez por semana, durante nove semanas para avaliação do perfil seminal. Os exames bioquímicos do sêmen foram realizados por mais dez semanas após o término das aplicações. E para a dosagem de testosterona sérica, foram realizadas colheitas de sangue nos cinco dias correspondentes às aplicações de dexametasona.

Análise estatística

Os resultados de frutose, ácido cítrico, porcentagem de defeitos morfológicos e concentração foram submetidos à análise estatística paramétrica por meio do teste ANOVA para comparar os grupos controle e tratado. Os resultados obtidos para testosterona, volume, $\mathrm{pH}$, motilidade, turbilhonamento e vigor foram submetidos à estatística nãoparamétrica por se tratarem de valores não normais ou homogêneos, sendo avaliados pelo teste Kruskall-Wallis para os mesmos grupos. Para ambos os testes foi utilizado um $P$ de 0,05 (diferenças significativas $P<0,05$ ).

\section{RESULTADOS}

Durante os quatro meses que compreenderam 0 experimento, incluindo 0 período pré e póstratamento, não houve alteração no comportamento sexual dos touros avaliados, sendo a libido dos mesmos mantida em pontuação 6 , segundo a classificação de CHENOWETH (1980), representando valor máximo.

Para as variáveis frutose, ácido cítrico, concentração e morfologia espermática, avaliadas por estatística paramétrica pelo teste ANOVA, não houve diferença estatística $(P>0,05)$ entre os grupos controle e tratado pré e pós tratamento (Tabela 1).

Tabela 1: Comparação entre gr upo controle e tratado pré e pós -tratamento com dexametasona em relação a frutose, ácido cítrico, concentração e morfologia espermática.

\begin{tabular}{lcccc}
\hline & $\begin{array}{c}\text { Frutose } \\
(\mathrm{ng} / \mathrm{dL})\end{array}$ & $\begin{array}{c}\text { Acido citrico } \\
(\mathrm{ng} / \mathrm{dL})\end{array}$ & $\begin{array}{c}\text { Concentração } \\
\left(\text { células } 10^{6} / \mathrm{mL}\right)\end{array}$ & $\begin{array}{c}\text { Morfologia } \\
(\%)\end{array}$ \\
\hline Pré-tratamento & & & & \\
Controle $(\mathrm{n}=3)$ & $339,05 \pm 31,04$ & $715,66 \pm 55,06$ & $1269,67 \pm 89,06$ & $10 \pm 0,92$ \\
Tratado $(\mathrm{n}=3)$ & $278,77 \pm 30,55$ & $597,81 \pm 68,19$ & $1418,14 \pm 66,96$ & $8 \pm 0,83$ \\
\hline Pós-tratamento & & & & \\
Controle $(\mathrm{n}=3)$ & $422,06 \pm 29,34$ & $889,05 \pm 47,85$ & $1464,23 \pm 61,96$ & $6 \pm 0,61$ \\
Tratado $(\mathrm{n}=3)$ & $412,82 \pm 28,97$ & $722,81 \pm 42,49$ & $1445,03 \pm 60,04$ & $7 \pm 0,54$ \\
\hline Valor $\mathrm{P}$ & 0,434062 & 0,551094 & 0,778565 & 0,761880 \\
\hline $\begin{array}{l}\text { Valores de } \mathrm{P}>0,05 \text { indicam que não houve diferença estatística } \\
\text { significativa }\end{array}$
\end{tabular}

Para as variáveis volume do ejaculado, $\quad \mathrm{pH}$, motilidade, turbilhonamento, vigor espermático e testosterona sanguínea, avaliadas por estatística não paramétrica pelo teste Kruskall-Wallis, houve diferença significativa $(P<0,05)$ somente para a testosterona (Tabela 2).

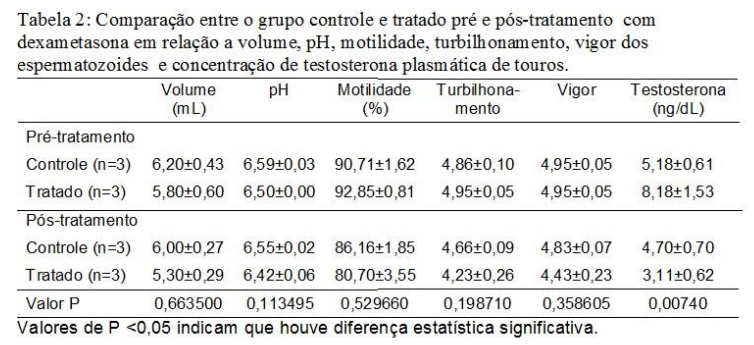

Para os níveis de testosterona sanguínea, observamos um decréscimo pós-tratamento, no grupo tratado (animais 1, 2, 3) (Figura 1). 


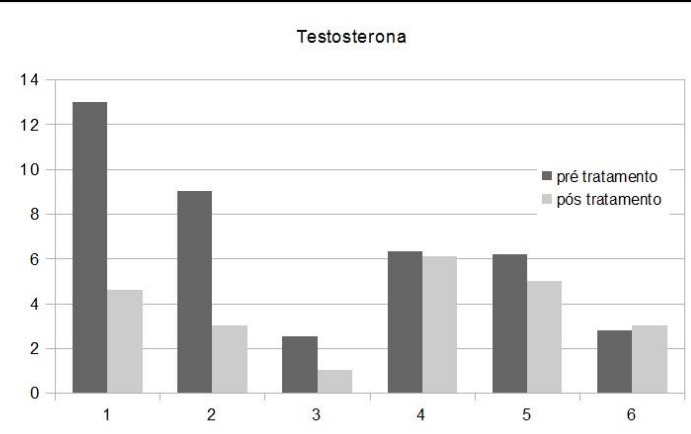

Figura 1: Comparação das médias dos valores de testosterona sérica entre o grupo tratado (animais 1, 2, 3) e controle (animais 4,5,6) pré e pós-tratamento.

\section{DISCUSSÃO}

No presente estudo, não se observaram diferenças significativas em relação aos grupos controle e tratado para 0 volume, turbilhonamento, motilidade, vigor, concentração espermática e porcentagem de defeitos dos espermatozoides, por se tratar de cinco aplicações consecutivas de dexametasona. Porém em outros trabalhos envolvendo um maior número de aplicações, observaram-se alterações nessas variáveis. HORN et al. (1999) demonstraram que a aplicação de $20 \mathrm{mg}$ de dexametasona por sete dias consecutivos em touros levou a um decréscimo qualitativo nos parâmetros avaliados (turbilhonamento, motilidade, vigor, concentração espermática e morfologia) devido a degeneração testicular leve induzida. TAHA et al. (1981) também observaram redução no volume do ejaculado e no número de espermatozoides, além do aumento na porcentagem de defeitos dos espermatozoides em cães tratados com $2 \mathrm{mg}$ de betametasona BID duas vezes por semana durante 5 semanas.

A frutose e o ácido cítrico do plasma seminal são importantes como fonte de energia metabólica e como componente de sistema tampão (GALIL E GALIL, 1982). Há evidências de que o nível de ácido cítrico no plasma seminal reflita o estado androgênico, já que existe uma correlação positiva com a testosterona sanguínea, estando ainda sujeito às variações estacionais, especialmente no garanhão e no bode (MAN et al. 1981). Em relação a frutose, ácido cítrico no plasma seminal e $\mathrm{pH}$ do sêmen, não ocorreram diferenças significativas entre os grupos controle e tratado, e não há trabalhos na literatura relacionando esta variável com a administração de glicocorticoides em touros.

A aplicação da dexametasona provocou diminuição na concentração sanguínea de testosterona nos touros (Tabela 2), fato este também encontrado por TOHEl et al. (1997) em ratos, WINGFIELD (2006) em marsupiais e BOLY et al. (1994) em touros em injeções intra testiculares. A diminuição da testosterona se deve ao efeito da dexametasona sobre a hipófise anterior, causando uma supressão na secreção de LH e, como consequência, a diminuição da secreção de testosterona pelas células de Leydig (THIEBER \& ROLLAND, 1976; WESTERHOF et al. 1994). Entretanto, de acordo com TOHEl et al. (1997) a queda nos níveis de testosterona seria por um efeito direto do corticoide sobre os receptores para LH. Para ALKASS (2009), não houve diferença significativa na concentração plasmática de testosterona em ovinos.

De acordo com TAHA et al. (1981), o declínio de testosterona sérica acompanhou atrofia testicular, ausência de libido, oligospermia e infertilidade em cães. Alguns desses fatos são corroborados por WEISS et al. (2003) em cães, que observaram retorno gradativo aos valores normais de testosterona sérica após o período do uso da dexametasona.

Mesmo ocorrendo diferença na concentração de testosterona sérica entre os grupos controle e tratado, a libido dos touros permaneceu inalterada durante todo 0 experimento sem apresentar variações quanto ao escore adotado para sua determinação. WEISS 
et al. (2003) também encontraram diminuição nos níveis de testosterona sérica, sem afetar o comportamento sexual de cães tratados com dexametasona.

Não se conhece o efeito causado pelo uso prolongado da dexametasona em touros. Porém em decorrência da diminuição da dosagem da testosterona sérica, presume-se que em longo prazo possa afetar a libido dos reprodutores e os demais parâmetros espermático envolvidos, uma vez que a espermatogênese seja dependente da testosterona nos machos. Desta forma, é importante a pesquisa com um grupo maior de animais que recebam a administração de dexametasona por um período maior de tempo para observar o efeito na fertilidade em longo prazo.

\section{CONCLUSÃO}

O uso da dexametasona em touros neste experimento não promoveu alteração significativa nos níveis de frutose, ácido cítrico no plasma seminal, volume, $\mathrm{pH}$, concentração, motilidade, turbilhonamento, vigor e defeitos morfológicos dos espermatozoides. No entanto, observou-se diminuição significativa na dosagem de testosterona sérica após cinco aplicações consecutivas de $20 \mathrm{mg}$ de dexametasona, sem que houvesse alteração na libido dos touros.

\section{REFERÊNCIAS}

Alkass, Z.M.Y. The effect of the dexamethasone on sperm characteristics and testosterone level on Awassi rams. Journal of Animal and Veterinary Advances, v.8, n.3, p.598602, 2009.

Boly, H.; Humblot, P.; Tillet, Y. Imunohistochemistry of $\mathrm{LH}$ and $\mathrm{FSH}$ secreting cells and response of plsma $\mathrm{LH}$ and testosterone to combined dexamethasone and $\mathrm{GnRH}$ treatment. Journal of Reproduction and Fertility, v.100, p.157-162, 1994.

Chenoweth, P.J. Libido and mating ability in bulls. In Morrow D.A. Current therapy in theriogenology, p.342-344. Philadelphia, W.B. Saunders, 1980.

Galii, K.A.A.; Galil, A.K.A. Seasonal variation in some characteristics of ejaculated spermatozoa of Sudan desert sheep in the tropics. Journal of Agricultural Science, v.99, n.1, p.3543, 1982.

Horn, M.M.; Moraes, J.C.F.; Galina, C.S. Qualidade do sêmen de touros das raças Aberdeen Angus e Branguslbagé em frente à degeneração testicular experimental induzida por dexametasona. Ciência Rural, v.29, n.3, 1999.

Mann, T.; Lutwak-Mann, C. Male reproductive function and semen. Springer-Verlag Berlin Heidelberg New York, 1981, p.495.

Nascimento, E.F.; Santos, R.L. Patologia da reprodução de animais domésticos. 2 ed. Rio de Janeiro: Guanabara Koogan, 2003, p.93-104.

Pimpão, C.T.; Rocha, R.M.V.M.; Schaefer, R.; Wouk, A.F.P.F.; Cirio, S.M.; Benato, E.M.; Gurgel, L.G.A.; Fronczak, M.A. Avaliação dos efeitos toxicológicos da ivermectina em cães. Archives of Veterinary Science, v.3, n.4, p. 19-24, 2005.

Taha, M.B.; Noaks, D.E.; Allen, W.E. The effect of some exogenous hormones on seminal characteristics, libido and peripheral plasma testosterone concentrations in the male Beagle. Journal of Small Animal Pratice, v.22, p.587-595, 1981.

Thibier, M.; Rolland, O. The effect of dexamethasone on circulating testosterone and luteinizing hormone in young postpubertal bulls. Theriogenology, v.5, n.2, p. 53-60, 1976. 
Tohei, A.; Tomabechi, T.; Mamada, M.; Akaim, M. Effects of repeated stress on the hypothalamic-pituitary-testes axis in adult rats. Journal of Veterinary Medical Science, v.59, p.329-334, 1997.

Vale Filho, V.R.; Megale, F.; Abreu, J.J.; Pinto, P.A.; Fonseca, J. Distúrbio da reprodução em touros Nelore, Gir, Guzerá, Indubrasil, comparativamente com touros das raças Holandês, Charolês e Chianina criados nas mesmas condições. In: SIMPÓSIO NACIONAL DE REPRODUÇÃO ANIMAL. Belo Horizonte. Proceeding... Belo Horizonte: Colégio Brasileiro de Reprodução Animal, p.8, 1981.

Van Camp, S.D. Common causes of infertility in the bull. Veterinary Clinics of North America: Food Animal Practice, v.13, p.203-30, 1997.

Weiss, R.R.; Amaral, M.C.; Büchele, J.M.; Messias, C. O efeito da dexametasona na fertilidade do cão. Revista Brasileira de Medicina Veterinária, v.1, n.1, p.30-34, 2003.

Westerhof, I.; Brom, W.E.; Mol, J.A. Sensitivity of the hypothalamicpituitaryadrenal system of pigeons. Avian Diseases, v.38, p.435-445, 1994.

Wingfield, J.C. Communicative behaviors, hormone-behavior interactions, and reproduction in vertebrates. Knobil and Neill's Physiology of Reproduction, v.3, 